\title{
Characterisation of Sorbus domestica L. Bark, Fruits and Seeds: Nutrient Composition and Antioxidant Activity
}

\author{
Boris Majić1,2, Ivana Šola ${ }^{1 *}$, Saša Likić ${ }^{1}$, Iva Juranović Cindrić ${ }^{2}$ and Gordana Rusak \\ ${ }^{1}$ Department of Biology, Faculty of Science, University of Zagreb, Horvatovac 102a, \\ HR-10000 Zagreb, Croatia \\ ${ }^{2}$ Department of Chemistry, Faculty of Science, University of Zagreb, Horvatovac 102a, \\ HR-10000 Zagreb, Croatia \\ Received: November 19, 2014 \\ Accepted: June 12, 2015
}

\begin{abstract}
Summary
The aim of this work is to assess the nutritional value of service tree (Sorbus domestica L.) bark, fruit exocarp and mesocarp, and seeds by establishing the levels of macro- and microelements, total phenolics, flavonoids and tannins. Our results revealed that all of the tested service tree samples were rich in potassium. Bark was the best source of calcium and zinc, while seeds were the best source of magnesium. Compared to the bark and seeds, fruit exocarp and mesocarp contained significantly lower amounts of these three elements. Immature exocarp and bark contained the highest amounts of total phenolics and showed the highest antioxidant activity. Maturation significantly decreased the amount of total phenolics in fruits, as well as the antioxidant activity of total phenolics and total tannins from exocarp, but not from mesocarp. Exocarp was the richest in total flavonoids. Based on the obtained data, we have concluded that the under-utilised species S. domestica L. could serve as an important source of mineral elements and antioxidants in the human diet.
\end{abstract}

Key words: service tree, food analysis, macroelements, microelements, phenolics, flavonoids, tannins, antioxidant activity

\section{Introduction}

The service tree (Sorbus domestica L.) is a deciduous species of the family Rosaceae self-sown in southern and central Europe, northern Africa, Asia Minor and Crimea (1). Its value has been recognized since Roman times; the fruit has been used as produce and its dense and highly valuable tough wood for crafting different mechanical parts. Nowadays it is considered a main (skeletal) tree for windbreaks and refuge for wildlife (2). It is also used for nutritional purposes (3) and has been proven useful for patients with diabetes (4). Furthermore, it is one of the twenty most frequently used traditional medicinal plants in the Kirklareli Province, Turkey (5). Just recently, wild service tree (S. torminalis L.) fruit water extract has been recognized as a natural source of acetylcholinesterase in- hibitors (6). In 2004, initial data on phenolic content in service tree fruits were published by Ölschläger et al. (7), who showed that the fruits contained procyanidins, cinnamic acids and flavonoid quercetin. More detailed data on the antioxidant activity of service tree fruits at different maturity stages were published by Termentzi et al. (3). In this paper, the authors revealed that fruit extracts possessed better radical scavenging activities than the commonly used antioxidant Trolox. Moreover, they showed that raw yellow fruits had the highest and the brown well-matured fruits (which are actually consumed) the lowest antioxidant activity. Later, it was revealed that there are small, but significant qualitative and obvious quantitative differences in the phenolic content among service tree fruits of different maturity stages (8). Likewise, the phenolic and antioxidant profiles strongly de- 
pend on the specific species of Sorbus L. fruits (9). Regarding other $S$. domestica L. parts, aqueous bark extract is used for stomach aches and ulcer treatment (5), but there are no data regarding its phenolic content. To the best of our knowledge, service tree seeds have not yet been used as food, and there are no data regarding their phenolic content. Tannin content (phenolics with a defensive role) in any service tree part is yet to be determined scientifically. Next to organic compounds (phenolics), the nutritional value of a plant and its extracts is also attributed to inorganic compounds (mineral elements) (10). An overview of relevant literature reveals that there are also no data on the mineral element composition of service tree species.

The relationship between the inadequate uptake of macro- and microelements and the occurrence of various diseases in humans has been documented by Mindell (11) and the World Health Organization (WHO) (12). According to Steinnes (13), some of the gravest health problems that affect over one billion people worldwide are associated with an inadequate supply of the trace elements iodine, selenium and/or zinc. Since trace elements are essential components of enzyme systems, their deficiencies also have profound effects on the metabolism and tissue structure (14).

Flavonoids are low molecular mass polyphenolics with a protective role in plants and a multitude of beneficial health effects on the human organism. Their health-promoting effects are based on antioxidant, antiproliferative, antitumour and anti-inflammatory activities (15). Flavonoids also act as antibacterial, antifungal and antiviral agents (16). Interestingly, flavonoid metal derivatives bind more effectively to viral double-stranded RNA than free flavonoids (17), which suggests that metal binding could enhance the antiviral effects of flavonoids. In S. domestica fruits from the mountainous region of Rodopi (northern Greece) two quercetin glycosides and a quercetin dimer, as well as a flavanol glycoside, were detected (18).

Tannins are complex polyphenolics commonly found in higher plants that form insoluble complexes with proteins. They are classified into two categories: hydrolysable and non-hydrolysable or condensed. In the food sector, interest in hydrolysable tannins has increased constantly due to their antioxidant (19), antibacterial and antiviral activity (20). So far, the bark of the European service tree has been used for tanning leather (21), but it is yet to be used in the food industry.

The aim of this study is to chemically characterise service tree bark, fruits (separately exocarp and mesocarp), and seeds collected in Croatia at the level of inorganic (macro- and microelements) and organic compounds (total phenolics, total flavonoids and total tannins). A detailed evaluation of the antioxidant activities of total phenolics and tannins was also conducted. Principal component analysis (PCA) was conducted to screen for the directions in which the samples varied considering the performed measurements. Knowledge about the nutritional value of this under-utilised species should lead to its better protection and dissemination, as well as to its more frequent use in the human diet as a valuable source of mineral elements and antioxidants.

\section{Materials and Methods}

\section{Plant material}

Service tree (Sorbus domestica L.) bark, fruits and seeds were collected in Mađari, a village near Sisak, Croatia $\left(45^{\circ} 29^{\prime} \mathrm{N} 16^{\circ} 22^{\prime} \mathrm{E}\right)$. Bark samples were collected on six occasions in 2011 (evenly separated) from one-year-old branches, dried for thirty days at room temperature and powdered in a grinder. Fruit samples were collected in September of 2009 and 2011, and divided into two categories: immature fruits (yellow colour) and well-matured fruits (brown colour), frozen under liquid nitrogen and lyophilized (Christ Alpha 1-2; Christ, Osterode am Harz, Germany), at $-60{ }^{\circ} \mathrm{C}$ and 0.01 mbar for $24 \mathrm{~h}$. Exocarp, mesocarp and seeds were stored separately in a desiccator. Before analysis, these samples were powdered in a mortar. The analysed S. domestica samples were: bark, exocarp of immature fruit, mesocarp of immature fruit, exocarp of mature fruit, mesocarp of mature fruit, and seeds.

\section{Chemicals and reagents}

Nitric acid, hydrogen peroxide, acetic acid, sodium carbonate decahydrate and Folin-Ciocalteu reagent were purchased from Kemika (Zagreb, Croatia). Casein, sodium acetate trihydrate, aluminium chloride, potassium acetate, quercetin, gallic acid, 1,1-diphenyl-2-picrylhydrazyl (DPPH) and 2,2'-azino-bis(3-ethylbenzothiazoline-6-sulphonic acid) (ABTS) were purchased from Sigma-Aldrich Chemie GmbH (Munich, Germany). Multielement standard (ICP Multielement Standard IV) and methanol LiChrosolv $^{\circledR}$ were purchased from Merck (Darmstadt, Germany).

\section{Determination of macro- and microelements}

\section{Microwave-assisted digestion}

A Berghof speedwave MWS-2 microwave system (Berghof Products+Instruments $\mathrm{GmbH}$, Eningen, Germany) was used for the microwave-assisted digestion of samples. The digestion procedure was conducted according to Juranović Cindrić et al. (22) with small adjustments. Three steps were undertaken (first: power $P=60 \%$ and $t=110{ }^{\circ} \mathrm{C}$, second: $P=75 \%$ and $t=170{ }^{\circ} \mathrm{C}$, and third: $P=50 \%$ and $t=140^{\circ} \mathrm{C}$ ), each lasting for $15 \mathrm{~min}$. For the microwave-assisted digestion approx. $50 \mathrm{mg}$ of the lyophilised or dried sample were weighed in a Teflon reaction vessel (in duplicate). After that, $5 \mathrm{~mL}$ of $\mathrm{HNO}_{3}$ (50:50 by volume) and $1 \mathrm{~mL}$ of $\mathrm{H}_{2} \mathrm{O}_{2}(1 \mathrm{M})$ were added.

\section{ICP-AES method}

Macro- and microelement content was determined using a Prodigy High Dispersion inductively coupled plasma atomic emission spectrometer (ICP-AES; Teledyne Leeman, Hudson, NH, USA) operated in simultaneous mode according to Juranović Cindrić et al. (22), with small adjustments. The working conditions were: high-resolution echelle spectrometer polychromator; large format programmable array detector (L-PAD); free-running radio frequency generator at $40 \mathrm{MHz}$; output power of 1.1 $\mathrm{kW}$; argon flow: coolant gas flow $18 \mathrm{~L} / \mathrm{min}$, auxiliary gas $0.8 \mathrm{~L} / \mathrm{min}$, nebulizer gas $1 \mathrm{~L} / \mathrm{min}$; peristaltic pump rate 1 
$\mathrm{mL} / \mathrm{min}$; glass concentric pneumatic nebulizer; glass cyclonic spray chamber; axial plasma viewing; three replicates for each analysis run; and sample uptake delay of $30 \mathrm{~s}$.

A multielement standard was used for the preparation of standard solutions in $2 \% \mathrm{HNO}_{3}$. The stock solution was diluted to obtain the following concentrations (in $\mathrm{mg} / \mathrm{mL}$ ): 20.0, 15.0, 10.0, 5.0, 2.0, 1.0, 0.5, 0.2, 0.1 and 0.05 . Blank solutions were prepared in the same medium. Calibration ranges were modified according to the expected concentration ranges of the elements of interest.

The emission lines selected for the determination of the elements were at the following wavelengths (in $\mathrm{nm}$ ): 206.149, 224.700, 213.856, 238.204, 231.604, 257.610, 308.215, 455.403, 407.771, 766.491, 396.847, 589.592 and 285.213 for $\mathrm{Cr}, \mathrm{Cu}, \mathrm{Zn}, \mathrm{Fe}, \mathrm{Ni}, \mathrm{Mn}, \mathrm{Al}, \mathrm{Ba}, \mathrm{Sr}, \mathrm{K}, \mathrm{Ca}, \mathrm{Na}$ and $\mathrm{Mg}$, respectively.

\section{Analysis of plant bioactive compounds \\ Extraction procedure}

Extraction was conducted according to Makkar et al. (23) with small adjustments. Briefly, $20 \mathrm{mg}$ of lyophilised plant material were extracted with $2 \mathrm{~mL}$ of $50 \%$ methanol during $45 \mathrm{~min}$ in a water bath $\left(80^{\circ} \mathrm{C}, 2 \times g\right)$. After centrifugation (10 $\left.\mathrm{min}, 11900 \times g, 4^{\circ} \mathrm{C}\right)$, the supernatant was collected. A basic solution containing tannins and a solution without tannins were prepared from the supernatant according to Rusak et al. (24). Briefly, $300 \mu \mathrm{L}$ of supernatant, $1.5 \mathrm{~mL}$ of sodium acetate trihydrate buffer and $1.2 \mathrm{~mL}$ of deionized water were mixed. One half of this solution was centrifuged ( $5 \mathrm{~min}, 16500 \times g$, room temperature) and the obtained supernatant contained tannins. The other half of the solution was vortexed with $7.5 \mathrm{mg}$ of casein, incubated at room temperature for $60 \mathrm{~min}$, and centrifuged ( $5 \mathrm{~min}, 16500 \times \mathrm{g}$, room temperature). This ensured that the obtained supernatant did not contain tannins.

Estimation of total phenolics and total tannins using the Folin-Ciocalteu method

The method by Rusak et al. (24) was adapted for absorbance reading in 96-well microtiter plates. The reaction mixtures for total phenolics (each solution contained sample+standard $+50 \%$ methanol, Folin-Ciocalteu reagent and $2 \%$ (by mass per volume) sodium carbonate) were applied onto 96-well microplates (Nunc ${ }^{\mathrm{TM}}$ V96 Micro-Well ${ }^{\mathrm{TM}}$ 96; Sigma-Aldrich Chemie $\mathrm{GmbH}$, Munich, Germany) and the absorbances were read at $740 \mathrm{~nm}$ using Fluostar Optima (BMG Labtech GmbH, Offenburg, Germany). The total phenolic and total tannin mass fractions were calculated from the calibration curve using gallic acid as a standard. The results were expressed in milligrams of gallic acid equivalents per gram of dry mass ( $\mathrm{mg}$ of GAE per $\mathrm{g} \mathrm{dm}$ ). The mass fractions of total phenolics were obtained from the absorbance of basic solution containing tannins, and those that belong to total tannins by subtraction of absorbance of the solution without tannins from that of the solution with tannins.

Estimation of total flavonoids using aluminium chloride

This analysis was conducted according to Ozsoy et al. (25) with small modifications. To be more precise, the reaction mixtures were applied onto 96-well microplates
(Nunc V96 MicroWell 96) and the absorbance was read at $405 \mathrm{~nm}$ using Fluostar Optima (BMG Labtech $\mathrm{GmbH}$ ). The total flavonoid mass fractions were calculated from the calibration curve using quercetin as a standard. The results were expressed in milligrams of quercetin equivalents per gram of dry mass (mg of QE per $\mathrm{g} \mathrm{dm}$ ).

\section{Evaluation of antioxidant activity using $\mathrm{DPPH}$}

The $\mathrm{DPPH}^{\cdot}$ method was implemented according to Termentzi et al. (3). The reaction mixtures were applied onto 96-well microplates (Nunc V96 MicroWell 96) and the absorbance was read at $520 \mathrm{~nm}$ using Fluostar Optima (BMG Labtech $\mathrm{GmbH}$ ). The results were expressed as antioxidant activity (AA). The AA of total tannins was calculated as follows:

$$
\mathrm{AA}_{\text {total tannins }}=\mathrm{AA}_{\text {solution with tannins }}-\mathrm{AA}_{\text {solution without tannins }}
$$

Evaluation of antioxidant activity using $\mathrm{ABTS}^{\cdot+}$

The ABTS radical cation $\left(\mathrm{ABTS}^{+}\right.$) decolourisation assay was conducted according to Rusak et al. (26). The reaction mixtures were applied onto 96-well microplates (Nunc V96 MicroWell 96) and the absorbance was read at $740 \mathrm{~nm}$ using Fluostar Optima (BMG Labtech $\mathrm{GmbH}$ ). The results were expressed as antioxidant activity of total tannins, calculated using Eq. 1.

\section{Statistical analysis}

All analyses were carried out in six replicates and the data were presented as mean values \pm standard deviation (S.D.). The statistical significance of the differences between the investigated groups was evaluated by factorial analysis of variance (ANOVA) and their mean values were compared using the Bonferroni correction. The differences were considered to be statistically significant at $p<0.05$. The relationships between the total phenolics and their antioxidant activity were investigated using Pearson's correlation coefficient. Patterns of (i) micro- and macroelements, and (ii) total phenolics, flavonoids, tannins and antioxidant efficiencies of total phenolics and tannins were analysed using PCA. A subset of components with the highest variances was used to visualise the data in a two-dimensional space.

\section{Results and Discussion}

The nutritional value of different parts of service tree (Sorbus domestica L.) was investigated by phytochemical analyses (by determination of macro- and microelements, total phenolic compounds, flavonoids and tannins, and determination of the antioxidant activity). Macro- and microelements are necessary for the structural and functional integrity of cells, tissues and organisms $(13,14,27)$. An imbalance of these elements in an organism causes metabolic disorders and health problems. One of the best ways to prevent macro- and/or microelement deficiencies is to enrich one's diet with food that contains a higher amount of these elements.

Since, to the best of our knowledge, until now no data have been published on the content of macro- and microelements in the service tree, we screened different 
parts of this species for the presence of these elements using inductively coupled plasma atomic emission spectrometry (ICP-AES).

\section{Macro- and microelement content}

The service tree samples were analysed for their macro- and microelement content after microwave digestion in aqueous $50 \% \mathrm{HNO}_{3}$ (by volume). The elements were divided into groups in accordance with $\mathrm{WHO}$ guidelines (12) and the results are given in Fig. 1. Results of the determination of the macroelements $\mathrm{K}, \mathrm{Ca}, \mathrm{Na}$ and $\mathrm{Mg}$ are given in Fig. 1a.

As can be seen, all of the tested service tree samples (bark, fruit exocarp and mesocarp, and especially seeds) proved to be good sources of $\mathrm{K}$. This macroelement ensures normal blood pressure maintenance and transmis-
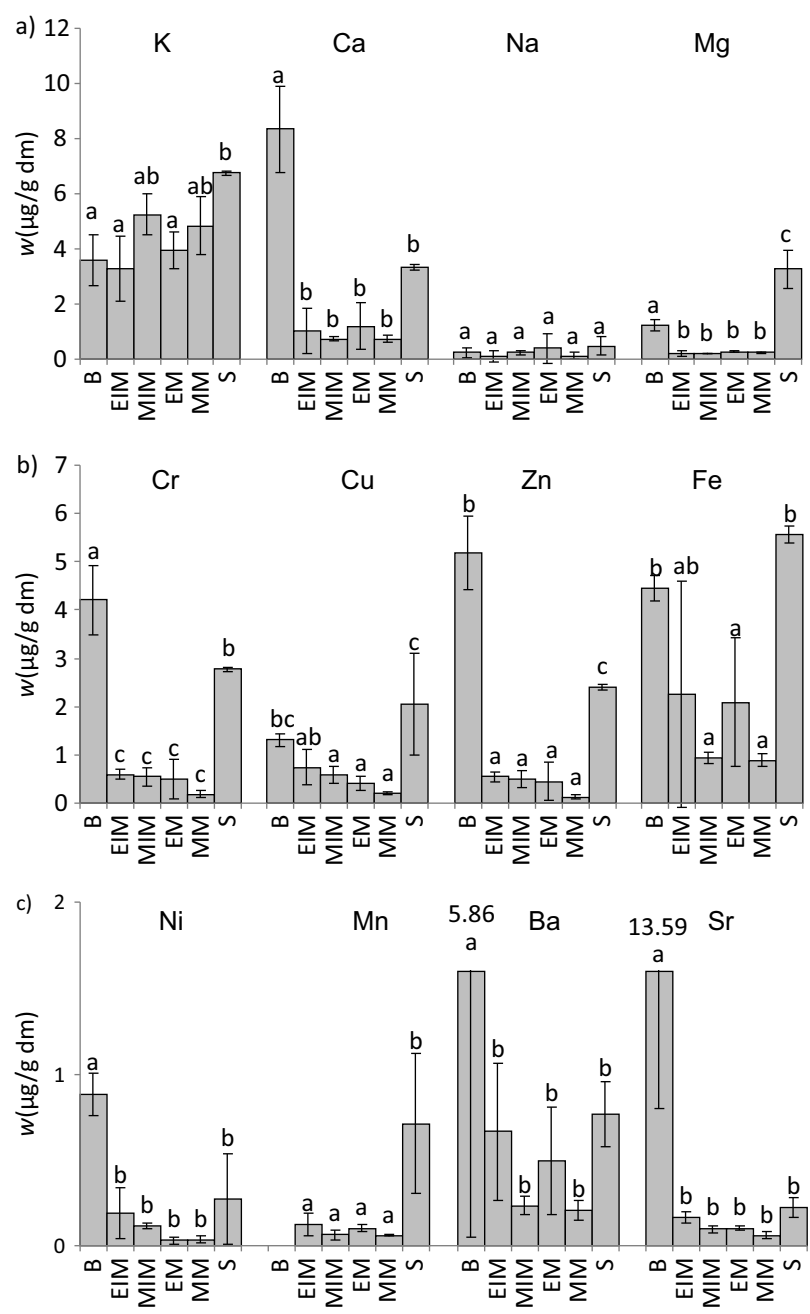

Fig. 1. Mass fractions of macro- and microelements on dry mass basis $(\mathrm{dm})$ in the extracts of bark, mature and immature exocarp and mesocarp, and seeds of service tree species: a) macroelements (K, $\mathrm{Ca}, \mathrm{Na}, \mathrm{Mg}), \mathrm{b}$ ) essential microelements ( $\mathrm{Fe}, \mathrm{Zn}, \mathrm{Cu}$, $\mathrm{Cr})$, and c) microelements that are probably essential $(\mathrm{Ni}, \mathrm{Mn})$ and potentially toxic $(\mathrm{Ba}, \mathrm{Sr})$. Values are expressed as mean \pm standard deviation (S.D.) based on six independent experiments. Mean values labelled with different letters are significantly different $(N=6, p<0.05$, factorial ANOVA, post hoc Bonferroni correction). $\mathrm{B}=$ bark, $\mathrm{EIM}=\mathrm{immature}$ exocarp, $\mathrm{MIM}=\mathrm{immature}$ mesocarp, $\mathrm{EM}=$ mature exocarp, $\mathrm{MM}=$ mature mesocarp, $\mathrm{S}=$ seeds sion of nerve impulses to muscles (11), and is therefore very important for human health. It can be concluded with reasonable certainty that service tree bark, exocarp, mesocarp and seed extracts could be used as natural sources of $\mathrm{K}$ in human nutrition.

Calcium is needed for various physiological processes in the human organism (it is a constituent of bones, it is required for normal blood clotting and maintenance of normal Na permeability in nerves, it serves as an intracellular signal for some hormones, etc.) (11). The best source of $\mathrm{Ca}$ among the tested samples was bark $(8.3 \mathrm{mg}$ per $\mathrm{g}$ $\mathrm{dm}$ ) followed by seeds ( $3.3 \mathrm{mg}$ per $\mathrm{g} \mathrm{dm}$ ). Interestingly enough, the fruit exocarp and mesocarp contained significantly lower amounts of $\mathrm{Ca}$ (in $\mathrm{mg}$ per $\mathrm{g} \mathrm{dm}$ ), immature exocarp 1.0, mature exocarp 1.2, immature mesocarp 0.7, and mature mesocarp 0.7. As Segura et al. (28) revealed, there are only a few foods rich in $\mathrm{Ca}$, e.g. cheese 7.21 , sardines canned in oil 3.82 and almonds $2.48 \mathrm{mg}$ per g of edible portion. Our results indicated that service tree bark and/or seed extracts may be added to that list.

Magnesium deficiency in the human body is known to cause cardiovascular diseases (29) and bone growth irregularities (11). Among our samples, service tree seeds contained the highest amount of $\mathrm{Mg}$, followed by bark, while fruit exocarp and mesocarp contained significantly lower amounts of Mg. According to Segura et al. (28), nuts contain more $\mathrm{Mg}$ than any other common edible plant (around $3 \mathrm{mg}$ per $\mathrm{g}$ of edible portion). Our results indicated that service tree seed and bark extracts contain 2.8 and $1 \mathrm{mg}$ per $\mathrm{g}$ of $\mathrm{dm}$, respectively. Accordingly, service tree seed and bark extracts could also be rich sources of Mg.

In comparison to $\mathrm{K}, \mathrm{Ca}$ and $\mathrm{Mg}$, all of the tested samples (with the exception of $\mathrm{Mg}$ in exocarp and mesocarp) contained a significantly lower amount of $\mathrm{Na}$. As a high intake of $\mathrm{K}, \mathrm{Ca}$ and $\mathrm{Mg}$ alongside a low Na intake are associated with protection against bone demineralisation, arterial hypertension and overall cardiovascular risk (29), our results indicated a good nutritional potential of service tree extracts. It is worth noting that, despite the significantly higher amount of $\mathrm{K}$ over $\mathrm{Na}$, the $\mathrm{K} / \mathrm{Na}$ ratio in our tested service tree extracts remained between 10.1 (mature exocarp) and 37.8 (mature mesocarp) (Fig. 1) and, according to Szentmihályi et al. (10), these values indicate that neither of the tested extracts should have diuretic activity. However, since flavonoids, saponind, volatile oils and ascorbic acid could also affect the diuretic activity of an extract (10), it would be interesting to test this activity in vivo.

Results of the determination of essential microelements $(\mathrm{Cr}, \mathrm{Cu}, \mathrm{Zn}$ and $\mathrm{Fe})$ are given in Fig. $1 \mathrm{~b}$. Generally, bark and seeds were richer in essential microelements $\mathrm{Fe}$, $\mathrm{Zn}, \mathrm{Cu}$ and $\mathrm{Cr}$ than exocarp and mesocarp.

Iron metabolism disorders are among the most common human diseases and encompass a broad spectrum ranging from anaemia to Fe overload and, possibly, to neurodegenerative diseases (30). Our measurements revealed that, among the tested samples, seeds, bark and immature exocarp were the richest in Fe.

Zinc is such a critical element in human health that even a small deficiency can be disastrous (31). It is essen- 
tial for cell division, DNA and protein synthesis, and therefore critical for numerous physiological processes. Our results indicated that service tree bark and seed extracts were significantly better sources of $\mathrm{Zn}$ than the fruits.

Copper is indispensable for blood vessel and nerve health as well as for the proper functioning of the immune system (11). According to our results, the bark and seeds contained higher mass fractions of $\mathrm{Cu}$ than the fruit exocarp and mesocarp. Therefore, bark and seed extracts could be used as supplemental sources of $\mathrm{Zn}$ and $\mathrm{Cu}$ in the human organisms.

Appropriate $\mathrm{Cr}$ intake is important for thyroid gland and insulin receptor metabolism (32). Our measurements revealed significantly higher mass fractions of $\mathrm{Cr}$ in service tree bark and seeds compared to exocarp and mesocarp $(\mathrm{p}<0.05)$, thus the bark and seeds could be used as sources of $\mathrm{Cr}$.

Regarding microelements that are probably essential, ( $\mathrm{Ni}$ and $\mathrm{Mn}$ ), and the potentially toxic microelements (Ba and $\mathrm{Sr}$ ), our data (Fig. 1c) indicated significantly more $\mathrm{Ni}$ in bark than in the other samples tested, but mass fraction of $\mathrm{Mn}$ in the bark was below detection limit, while the highest mass fraction of Mn was determined in the seeds.

The mass fractions of $\mathrm{Ba}$ and $\mathrm{Sr}$ recorded in the bark were extremely high and therefore questionable; the most probable reason for this was contamination - specifically, only bark samples were chopped using a grinder. Therefore, another method of bark grinding should be applied to verify these data.

\section{Total phenolic, tannin and flavonoid contents}

The beneficial effects of service tree bark, fruits and leaves on human health have already been established $(3,5)$. Termentzi et al. (8) suggested that the amount of total phenolics could be responsible for a great number of these effects. Nevertheless, studies on service tree plant bioactive compounds are still very scarce $(3,8)$. Therefore, an additional task within this study was to establish the content of total phenols, flavonoids and tannins, define the antioxidant activity of the service tree samples, and compare the obtained results with those recorded for one of the most common fruits in the human diet (apple cultivars). The amount of plant bioactive compounds and their antioxidant activity were determined in bark, fruit exocarp and mesocarp and seeds. Moreover, exocarp and mesocarp were investigated in both their mature and immature stages in order to screen for an effect of maturation on fruit bioactive compound content and antioxidant activity. Amounts of total phenols, flavonoids and tannins in the service tree samples are given in Fig. 2. Levels of total phenols ranged from 0.5 to $105.6 \mathrm{mg}$ of GAE per $\mathrm{g}$ of $\mathrm{dm}$. Among the tested extracts, those of bark and immature exocarp contained the highest amounts of total phenols. Such results were expected; immature fruit exocarp should have high content of total tannins, which defend the seeds from various injuries and herbivores (33), while high levels of total flavonoids defend seeds from UV-B radiation (34). To be more specific, immature fruit exocarps are situated on the branches and are more exposed to the sunlight than mature fruit exocarps, which have likely fallen to the ground (35). Furthermore, high content of phenols in bark extract was expected since bark has a defensive role mainly accomplished by tannins (33). The amount of total phenols in fruits decreased upon maturation. Exocarp had a significantly higher amount of total phenols than mesocarp $(\mathrm{p}<0.05)$ in both the mature and immature stages, and a similar distribution was revealed in different apple cultivars by Henríquez et al. (36). To the best of our knowledge, only one study on service tree phenolic content has been published so far by Termentzi et al. (3), establishing phenolic content at four maturity stages of service tree fruit. For comparison with our results, we used their results for phenolic content in water and absolute methanol extracts (because water and methanol are most similar to the $50 \%$ aqueous methanol extracts we used), and concluded that in all of our samples the recorded content of total phenols was higher. We assume that the most probable reason for such differences were the different solvent and extraction methods used. Since Mukhopadhyay et al. (37) suggested $60 \%$ aqueous methanol (water enhances methanol penetration into the material) and $90{ }^{\circ} \mathrm{C}$ as the most favourable conditions for
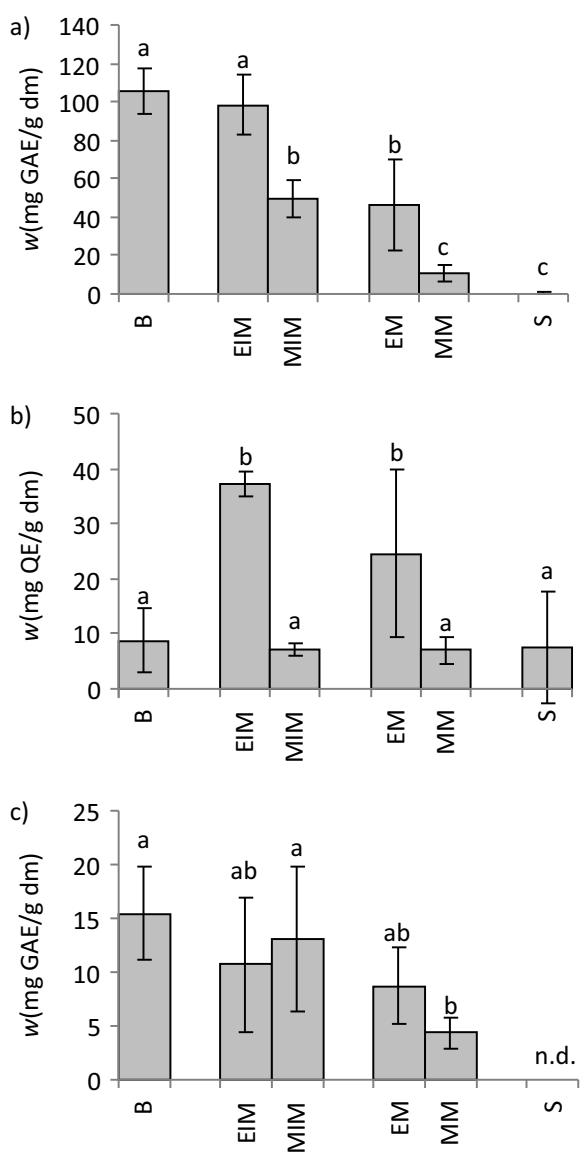

Fig. 2. Mass fractions of: a) total phenols, b) flavonoids and c) tannins in the extracts of bark, mature and immature exocarp and mesocarp, and seeds of service tree species. Values are expressed as mean \pm standard deviation (S.D.) based on six independent experiments. Mean values labelled with different letters are significantly different $(N=6, p<0.05$, factorial ANOVA, post hoc Bonferroni correction). B=bark, EIM=immature exocarp, $\mathrm{MIM}=\mathrm{immature}$ mesocarp, $\mathrm{EM}=$ mature exocarp, $\mathrm{MM}=$ mature mesocarp, $\mathrm{S}=$ seeds, n.d.=not detected, $\mathrm{GAE}=$ galic acid equivalent, $\mathrm{QE}=$ quercetin equivalent, $\mathrm{dm}=\mathrm{dry}$ mass 
maximal phenolic extraction efficiency, we presume our results are closer to the true phenolic content of service tree fruits than those obtained by Termentzi et al. (3) with absolute methanol or water at $100{ }^{\circ} \mathrm{C}$.

The mass fractions of total flavonoids are given in Fig. $2 \mathrm{~b}$. They ranged from 6.8 to $37.0 \mathrm{mg}$ of quercetin equivalents per $\mathrm{g}$ of $\mathrm{dm}$. The highest mass fractions of total flavonoids were recorded in the exocarp (mature and immature). Maturation did not significantly affect $(p<0.05)$ the flavonoid content either in the exocarp, or the mesocarp. Much like with service tree phenolic content, only one study with its flavonoid content has been published so far. Termentzi et al. (8) also established flavonoid content at four maturity stages of the service tree fruit using absolute methanol as extraction solvent. For comparison, we recorded higher content of total flavonoids in all of the tested samples. As in the case of total phenols, the reason for the difference could lie in the used solvents: we used aqueous methanol (50\%) as an extraction solvent, and since Sultana et al. (38) revealed that aqueous methanol is a better solvent for flavonoids than absolute methanol, we can once again presume with reasonable safety that our results are closer to the true amount of total flavonoids in service trees.

The mass fractions of total tannins are given in Fig. 2c. Levels ranged from 4.4 to $15.4 \mathrm{mg}$ of GAE per $\mathrm{g}$ of $\mathrm{dm}$. The only statistically significant difference in tannin content was observed between bark and immature mesocarp extracts and mature mesocarp extract. In seeds, the mass fractions of total tannins were below the detection limit. Bark was expected to contain higher mass fraction of tannins since these compounds have a defensive role (33). After maturation, as expected, mesocarp lost a significant amount of tannins. It is then logical to assume that the phenolic content should also decrease in mature mesocarp, and our experimental results corroborated this. Moreover, according to the data, we have concluded that the decreased level of phenols in mature mesocarp was caused by the loss of tannins during maturation. Among the samples, the highest amount of flavonoids was recorded in the exocarp (both mature and immature), while bark and mesocarp contained similar mass fractions of total flavonoids. Also, the most pronounced difference among the tested samples was recorded in the mass fractions of total flavonoids.

The analysis of the mass fractions of total phenols, flavonoids and tannins as well as the antioxidant activity of the extracts of phenols and tannins from service tree seeds resulted in relatively low values and large standard deviations, compared with other service tree samples. The obtained results led us to conclude that the applied preparation and extraction methods were obviously not suitable for the intended analysis of seeds.

\section{Antioxidant activity}

The antioxidant activity of total phenols and tannins extracted from the service tree samples is given in Fig. 3. Results of the DPPH' assay are given in Figs. 3a and c, while the results of $\mathrm{ABTS}^{-+}$assay are given in Figs. $3 \mathrm{~b}$ and d. Both methods showed higher antioxidant activity of phenolic extracts than of tannins, as expected. The values obtained using DPPH' were higher, and differences among the samples were more pronounced; therefore, we accepted these results as more reliable. Accordingly, immature exocarp and bark phenolic extracts had the highest antioxidant activity among the tested extracts, which was not surprising since immature exocarp and bark extracts also contained the highest mass fractions of total
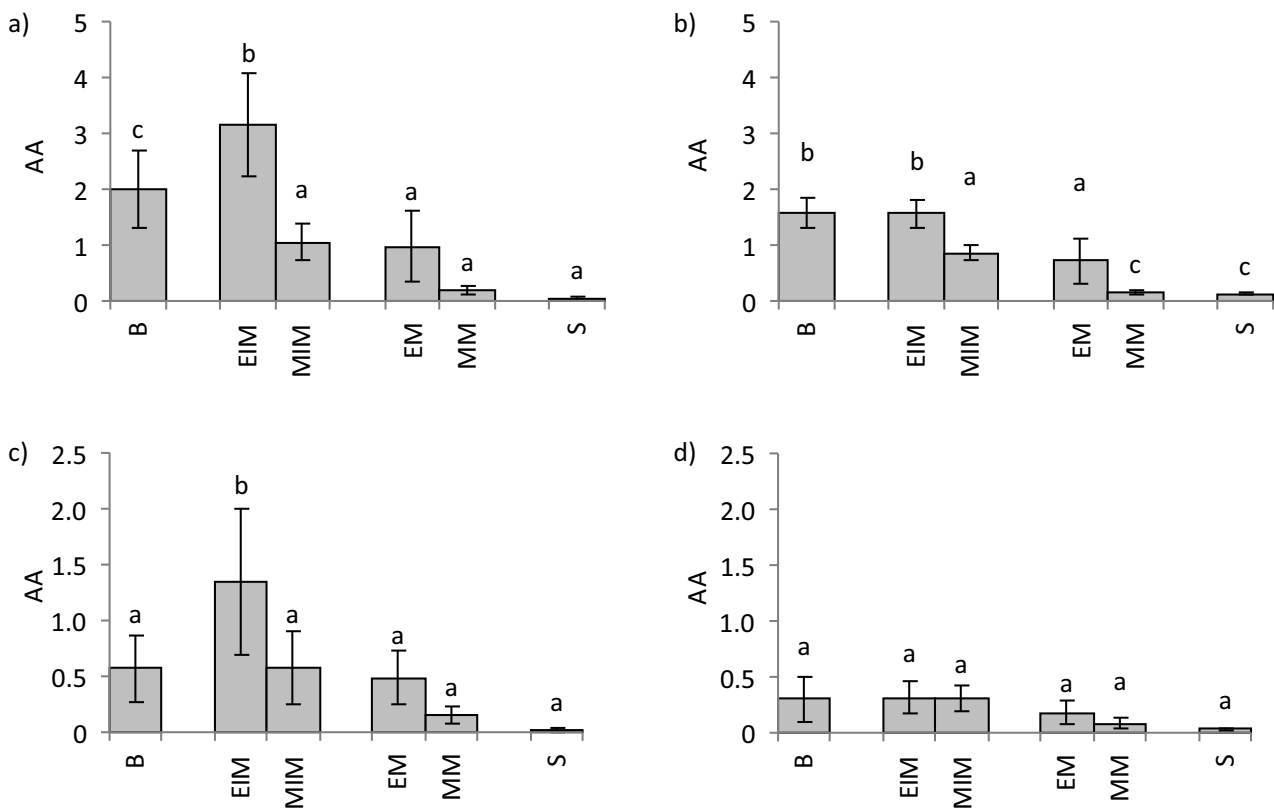

Fig. 3. Antioxidant activity (AA) of: a) total phenols and b) total tannins from the extracts of bark, mature and immature exocarp and mesocarp, and seeds of service tree species determined with $\mathrm{DPPH}^{-}$(a and $\mathrm{c}$ ), and $\mathrm{ABTS}^{+{ }^{+}}$method $(\mathrm{b}$ and d). Values are expressed as mean \pm standard deviation (S.D.) based on six independent experiments. Mean values labelled with different letters are significantly different $(N=6, p<0.05$, factorial ANOVA, post hoc Bonferroni correction). B=bark, EIM=immature exocarp, MIM=immature mesocarp, $\mathrm{EM}=$ mature exocarp, $\mathrm{MM}=$ mature mesocarp, $\mathrm{S}=$ seeds 
phenols. The high correlation coefficients between the phenolic content of the samples and their antioxidant activity $\left(\mathrm{R}^{2}\left(\mathrm{DPPH}^{*}\right)=0.927\right.$ and $\left.\mathrm{R}^{2}\left(\mathrm{ABTS}^{+}\right)=0.996\right)$ confirmed a strong positive linear relationship between these two variables. In comparison, the antioxidant activity of tannins was significantly higher only in the extract of immature exocarp; however, this result cannot be directly related to the mass fraction of total tannins in the tested samples since, compared to bark, immature exocarp did not contain a higher mass fraction of total tannins. The antioxidant activity of both total phenols and total tannins from exocarp significantly decreased after maturation, while the antioxidant activity of mesocarp total phenols and total tannins was not significantly affected by the maturation. The antioxidant activity of immature exocarp phenols and tannins was significantly higher than of mesocarp; however, in the mature stage it did not differ significantly $(\mathrm{p}<0.05)$. Henríquez et al. (36) established, using the FRAP assay, that in different cultivars of apple, at the technologically ripe stage, phenolic extracts of exocarp showed higher antioxidant activity than those of mesocarp; for comparison, we recorded that the antioxidant activity of total phenols in mature exocarp and mesocarp of service tree did not differ significantly $(p<0.05)$, but those in immature exocarp and mesocarp did. To the best of our knowledge, the study by Termentzi et al. (3) mentioned earlier is also the only one to examine the antioxidant activity of service tree samples. The fact that we recorded lower results in comparison with that study could be due to the different solvent and extraction method which could have caused lower yields of total phenols in the extracts and thus lower antioxidant activity of samples.
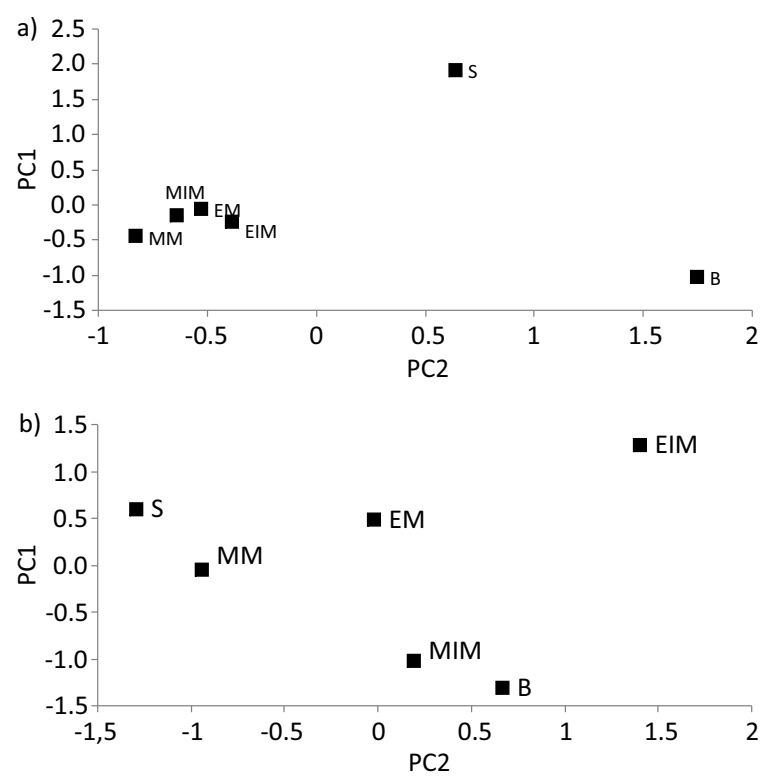

Fig. 4. Principal component analysis score plot of: a) macroand microelement profiles in the tested samples, b) mass fractions of total phenols, flavonoids and tannins, and antioxidant activity of total phenolic and tannin extracts. PC1 vs. PC2 performed on selected variables had absolute loading values of elements higher than 0.95 and higher than 0.93 of organic compounds and their antioxidant efficiencies. B=bark, EIM=immature exocarp, $\mathrm{MIM}=\mathrm{immature}$ mesocarp, $\mathrm{EM}=$ mature exocarp, $\mathrm{MM}=$ mature mesocarp, $\mathrm{S}=$ seeds

\section{Principal component analysis}

The data we obtained from the service tree samples were subjected to PCA with the aim to identify the principal directions in which the samples vary. At the level of the tested mineral nutrients, the bark and seed profiles clearly differed from one another as well as from the fruit sample profiles, which were more similar among each other (Fig. 4a). At the level of the tested organic compounds and their antioxidant activity, immature exocarp was separated from the other tested samples (Fig. 4b).

\section{Conclusions}

Generally, service tree bark and seeds were better sources of macro- and microelements than fruit exocarp and mesocarp. All of the tested service tree samples were rich in $\mathrm{K}$. The best source of $\mathrm{Ca}$ among the tested samples was bark followed by seeds. The seeds contained the highest mass fraction of $\mathrm{Mg}$, followed by bark; fruit exocarp and mesocarp contained significantly lower mass fractions of both $\mathrm{Ca}$ and $\mathrm{Mg}$. Bark and seeds were also a far better source of essential microelements $\mathrm{Fe}, \mathrm{Zn}, \mathrm{Cu}$ and $\mathrm{Cr}$ than exocarp and mesocarp. Seeds and bark contained the highest amount of $\mathrm{Fe}$, while bark was the best source of $\mathrm{Zn}$.

Bark and immature exocarp contained the highest mass fractions of total phenols. Exocarp had a significantly higher mass fraction of total phenols than mesocarp $(p<0.05)$ in both the mature and immature stages. The maturation process decreased the amount of total phenols in fruits (both exocarp and mesocarp). Moreover, we have revealed that during maturation, mesocarp loses a significant amount of total tannins. Exocarp was significantly richer in total flavonoids than mesocarp in both the immature and mature stages. By far the highest mass fraction of total flavonoids was recorded in exocarp (both mature and immature), while bark and mesocarp contained a similar mass fraction of total flavonoids. The phenolic extracts of service tree had higher antioxidant activity than tannin extracts. Extracts of total phenols from immature exocarp and bark had the highest antioxidant activity among the tested extracts. In comparison, the antioxidant activity of total tannins was significantly higher only in the immature exocarp extract. The maturation process significantly decreased the antioxidant activity of total phenols and tannins in the exocarp, but not from mesocarp.

Finally, service tree bark could be used as a good source of $\mathrm{Ca}, \mathrm{Zn}, \mathrm{Fe}$ and total phenols, while the seeds could be used as a good source of $\mathrm{K}, \mathrm{Mg}, \mathrm{Fe}$ and $\mathrm{Zn}$. Immature exocarp proved to be a great source of total phenols and flavonoids. Based on the data obtained within this study, we can conclude that different parts of Sorbus domestica L. could be used as quality sources of the mineral elements and antioxidants important for the human diet. Knowledge about the nutritional value of this under-utilised species highlights the need for its protection and dissemination.

\section{Acknowledgements}

This research was not financially supported. 


\section{References}

1. Drvodelić D, Oršanić M, Jemrić T. Morphological characteristics of fruits and seed of the service tree (Sorbus domestica L.). Radovi (Hrvat šumar inst) 2009;44:5-15 (in Croatian).

2. Paganová V. Ecological requirements of wild service tree (Sorbus torminalis [L.] Crantz.) and service tree (Sorbus domestica L.) in relation with their utilization in forestry and landscape. J For Sci. 2008;54:216-26.

3. Termentzi A, Kefalas P, Kokkalou E. Antioxidant activities of various extracts and fractions of Sorbus domestica fruits at different maturity stages. Food Chem. 2006;98:599-608. http://dx.doi.org/10.1016/j.foodchem.2005.06.025

4. Termentzi A, Alexiou P, Demopoulos VJ, Kokkalou E. The aldose reductase inhibitory capacity of Sorbus domestica fruit extracts depends on their phenolic content and may be useful for the control of diabetic complications. Pharmazie. 2008;63:693-6. http://dx.doi.org/10.1691/ph.2008.8567

5. Kültür S. Medicinal plants used in Kırklareli Province (Turkey). J Ethnopharmacol. 2007;111:341-64. http://dx.doi.org/10.1016/j.jep.2006.11.035

6. Hasbal G, Yilmaz-Ozden T, Can A. Antioxidant and antiacetylcholinesterase activities of Sorbus torminalis (L.) Crantz (wild service tree) fruits. J Food Drug Anal. 2015;23:57-62. http://dx.doi.org/10.1016/j.jfda.2014.06.006

7. Ölschläger C, Milde J, Schempp H, Treutter D. Polyphenols and antioxidant capacity of Sorbus domestica L. fruits. J Appl Bot Food Qual. 2004;78:112-6.

8. Termentzi A, Kefalas P, Kokkalou E. LC-DAD-MS (ESI+) analysis of the phenolic content of Sorbus domestica fruits in relation to their maturity stage. Food Chem. 2008;106:123445.

http://dx.doi.org/10.1016/j.foodchem.2007.07.021

9. Raudonis R, Raudone L, Gaivelyte K, Viškelis P, Janulis V. Phenolic and antioxidant profiles of rowan (Sorbus L.) fruits. Nat Prod Res. 2014;28:1231-40. http://dx.doi.org/10.1080/14786419.2014.895727

10. Szentmihályi K, Kéry Á, Then M, Lakatos B, Sándor Z, Vinkler P. Potassium-sodium ratio for the characterization of medicinal plant extracts with diuretic activity. Phytother Res. 1998:12:163-6.

http://dx.doi.org/10.1002/(SICI)1099-1573(199805)12:3<163: :AID-PTR217>3.0.CO;2-Y

11. Mindell E. The healing power of vitamins and minerals: from A to Z. In: Mindell E, editor. Food as medicine. Zagreb, Croatia: Mozaik knjiga; 1998. pp. 25-69 (in Croatian).

12. World Health Organization (WHO). Trace elements in human nutrition and health. Geneva, Switzerland: World Health Organization; 1996.

13. Steinnes E. Soil and human health. In: Sauer TJ, Norman JM, Sivakumar MVK, editors. Sustaining soil productivity in response to global climate change: science, policy, and ethics. Oxford, UK: Wiley-Blackwell; 2011. pp. 214-39. http://dx.doi.org/10.1002/9780470960257.ch6

14. Soetan $\mathrm{KO}$, Olaiya CO, Oyewole OE. The importance of mineral elements for humans, domestic animals and plants: a review. Afr J Food Sci. 2010;4:200-22.

15. Buer CS, Imin N, Djordjevic MA. Flavonoids: new roles for old molecules. J Integr Plant Biol. 2010;52:98-111. http://dx.doi.org/ 10.1111/j.1744-7909.2010.00905.x

16. Havsteen $\mathrm{BH}$. The biochemistry and medical significance of the flavonoids. Pharmacol Therapeut. 2002;96:67-202. http://dx.doi.org/10.1016/S0163-7258(02)00298-X

17. Rusak G, Piantanida I, Bretschneider S, Ludwig-Müller J. Complex formation of quercetin with lanthanum enhances binding to plant viral satellite double stranded RNA. J Inorg
Biochem. 2009;103:1597-601.

http://dx.doi.org/10.1016/j.jinorgbio.2009.08.008

18. Termentzi A, Zervou M, Kokkalou E. Isolation and structure elucidation of novel phenolic constituents from Sorbus domestica fruits. Food Chem. 2009;116:371-81. http://dx.doi.org/10.1016/j.foodchem.2009.02.019

19. Okuda T, Ito H. Tannins of constant structure in medicinal and food plants-hydrolyzable tannins and polyphenols related to tannins. Molecules. 2011;16:2191-217. http://dx.doi.org/10.3390/molecules16032191

20. Buzzini P, Arapitsas P, Goretti M, Branda E, Turchetti B, Pinelli $\mathrm{P}$, et al. Antimicrobial and antiviral activity of hydrolysable tannins. Mini-Rev Med Chem. 2008;8:1179-87. http://dx.doi.org/10.2174/138955708786140990

21. Ciesla WM. Non-wood forest products from temperate broad-leaved trees. In: Ciesla WM, editor. Non-wood forest products. Rome, Italy: Food and Agriculture Organization of the United Nations; 2002. pp. 54.

22. Juranović Cindrić I, Zeiner M, Krpetić M, Stingeder G. ICP-AES determination of minor and major elements in Cornelian cherry (Cornus mas L.) after microwave assisted digestion. Microchem J. 2012;105:72-6. http://dx.doi.org/10.1016/j.microc.2012.03.011

23. Makkar HPS, Blümmel M, Borowy NK, Becker K. Gravimetric determination of tannins and their correlations with chemical and protein precipitation methods. J Sci Food Agric. 1993;61:161-5. http://dx.doi.org/10.1002/jsfa.2740610205

24. Rusak G, Kuštrak D, Maleš Ž, Pleše N. The determination of the content of the polyphenols in the areal parts of the species Centaurea rupestris L. and C. fritschii Hayek (Asteraceae). Acta Pharm. 1993;43:121-5.

25. Ozsoy N, Can A, Yanardag R, Akev N. Antioxidant activity of Smilax excelsa L. leaf extracts. Food Chem. 2008;110:57183. http://dx.doi.org/10.1016/j.foodchem.2008.02.037

26. Rusak G, Komes D, Likić S, Horžić D, Kovač M. Phenolic content and antioxidative capacity of green and white tea extracts depending on extraction conditions and the solvent used. Food Chem. 2008;110:852-8.

http://dx.doi.org/10.1016/j.foodchem.2008.02.072

27. Ronen E. Micro-elements in agriculture. Prac Hydroponic Greenhous. 2007;1:39-48.

28. Segura R, Javierre C, Lizarraga MA, Ros E. Other relevant components of nuts: phytosterols, folate and minerals. $\mathrm{Br} \mathrm{J}$ Nutr. 2006;96:S36-44. http://dx.doi.org/10.1017/BJN20061862

29. Cappuccio FP. Sodium, potassium, calcium and magnesium and cardiovascular risk. J Cardiovasc Risk. 2000;7:1-3.

30. Lieu PT, Heiskala M, Peterson PA, Yang Y. The roles of iron in health and disease. Mol Asp Med. 2001;22:1-87. http://dx.doi.org/10.1016/S0098-2997(00)00006-6

31. Bhowmik D, Chiranjib KP, Kumar KPS. A potential medicinal importance of zinc in human health and chronic disease. Int J Pharm Biomed Sci. 2010;1:5-11. http://www.pharmainterscience.com/Docs/IJPBS-2010-01-02. pdf

32. Cefalu TW, Hu BF. Role of chromium in human health and in diabetes. Diabetes Care. 2004;27:2741-51. http://dx.doi.org/10.2337/diacare.27.11.2741

33. Pevalek-Kozlina B. Surface protection and defence compounds. In: Pevalek-Kozlina B, editor. Plant physiology. Zagreb, Croatia: Profil; 2003. pp. 485-6 (in Croatian).

34. Stapleton AE, Walbot V. Flavonoids can protect maize DNA from the induction of ultraviolet radiation damage. Plant Physiol. 1994;105:881-9. http://dx.doi.org/10.1104/pp.105.3.881 
35. Solovchenko A, Schmitz-Eiberger M. Significance of skin flavonoids for UV-B protection in apple fruits. J Exp Bot. 2003; 54:1977-84

http://dx.doi.org/10.1093/jxb/erg199

36. Henríquez C, Almonacid S, Chiffelle I, Valenzuela T, Araya M, Cabezas L, et al. Determination of antioxidant capacity, total phenolic content and mineral composition of different fruit tissue of five apple cultivars grown in Chile. Chil J Agr Res. 2010;70:523-36.
37. Mukhopadhyay S, Luthria LD, Robbins JR. Optimization of extraction process for phenolic acids from black cohosh (Cimicifuga racemosa) by pressurized liquid extraction. J Sci Food Agric. 2006;86:156-62. http://dx.doi.org/10.1002/jsfa.2326

38. Sultana B, Anwar F, Ashraf M. Effect of extraction solvent/ technique on the antioxidant activity of selected medicinal plant extracts. Molecules. 2009;14:2167-80.

http://dx.doi.org/10.3390/molecules14062167 